\title{
Proposing MRSCC (Mind Reading Silicon Clock Chip) - A Skill Transformation Method between Human and Robot
}

\author{
Rimmy Chuchra \\ Department of Computer Science \& Engineering \\ Sri Sai College of Engg and Technology, \\ Mannawala (Amritsar)
}

\begin{abstract}
Skill transformation from the human to the robot is really difficult task because of both are dissimilar bodies. This idea of skill transformation can be inspired by authors by proposing MRSCC (Mind Reading Silicon Clock Chip). The goal of this paper is to copy the contents of human brain into robot memory by simply inserting a silicon memory clock chip into robot machine correspondingly this designed methodology also create a permanent human memory backup of human brain. Such type of mind file is called Brain Back-Up. By utilizing this Digital Immorality concept robot will directly learns from a human without training and teaching that ultimately reduces human burden. This silicon memory clock chip act as an interface or bridge between the human and robot. In the absence of interface the transformation of skills from human to robots is impossible. On the time of skill transformation everything is stored in silicon memory chip that is inserted in human brain. By utilizing this designed methodology human brain downloading will be possible in robot machine. This designed methodology uses "store-and-forward technique". The benefit to use store and forward technique is: provide collaborative learning, time saving during skill transformation that leads to the reduction of effort applied by the human on the time of training. In addition, it also provides a closer view of humanrobot interaction that sometimes also called "Robot Fostering". Limited literature is available in mind uploading [44].
\end{abstract}

\section{Keywords}

Mind Reading silicon memory clock chip, Robot Fostering, Human-Robot Interaction, Mind Uploading, mind downloading, wireless camera, wireless antenna.

\section{INTRODUCTION}

Human-Robot Interaction is a highly interdisciplinary field that shows mutual interaction [14] and collaborative behavior [13] during communication. This communication channel provides various psychological approaches for providing different types of interactions at separate modes [29] viz. coexisting, conditional and essential mode [1]. The main aim of HRI is to provide a natural communication medium between the human and robot while utilizing several interfaces during the exchange of the information in any environment. It mainly utilizes two special types of interactions during information exchange from the human to the robot viz. remote interactions and proximate interactions [30].

$\checkmark \quad$ Remote Interactions: -While utilizing such type of interaction mode robotics are separated either spatially or temporary as an example robot can be operated with a remote under some specific area of range.

\author{
Prabhdeep Kaur \\ Department of Computer Science \& Engineering \\ Sri Sai College of Engg and Technology, \\ Mannawala (Amritsar)
}
$\checkmark \quad$ Proximate Interactions: - Both are co-located $\neg$ in the same room as an example human give command to robotics for performing any task.

They may use any type of interaction mode during communication. As we all know humans have ability to learn new skills either from the environment or from others where learning may be of any type that can be listed below:

$\begin{array}{ll}\checkmark & \text { Social Learning. } \\ \checkmark & \text { Active Learning. } \\ \checkmark & \text { Passive Learning. } \\ \checkmark & \text { Reinforcement Learning.[3] }\end{array}$

As researchers noticed, robot developers or robot designers spend their maximum time for teaching robot as an example for providing training to robots they most of the times uses reinforcement learning [8] [5] [15] [2] [6]. The benefit to utilize reinforcement learning is it gives behavior based feedback [56] from the environment that correspondingly provide a more natural view of human robotic interaction where the most popular methods are listed below:

$\checkmark$ Online motion generation method of robotic manipulators that helps to detect the location of dynamic obstacles through interactions [26].

$\checkmark \quad$ By utilizing touch technology sensor method provides a natural way of interaction [29].

$\checkmark$ Computer vision technique with remote interactions method [27].

Different types of natural interaction method show user friendly [4] and interactive behavior between human and robot [28]. This closer natural view of interaction sometimes also called "Robot Fostering" [25] [4]. This concept is easily implemented in CAD Programming that may run on offline mode [23] and shows its independent behavior during task performance. The complete working is only depend on the type of programming logic implemented on it as well as dataset consideration on the type of input applied. The main two broad categories of input are viz. homogeneous and heterogeneous. Homogeneous consider the same type of data elements whereas heterogeneous means the different types of data elements. The implementation of homogeneous tasks is very easy as compared to heterogeneous tasks because of robots shows robustness in behavior that can be managed independently [44].This paper study considers a set of heterogeneous elements in space where robots plays a distinct role while collecting information from different planets [20] [17] [18].

This paper proposes a new methodology that is termed as MRSCC (Mind Reading Silicon Clock Chip). Skills can be 
easily transferred from human to robot by utilizing any interface [12] that can be shown in fig.1:-

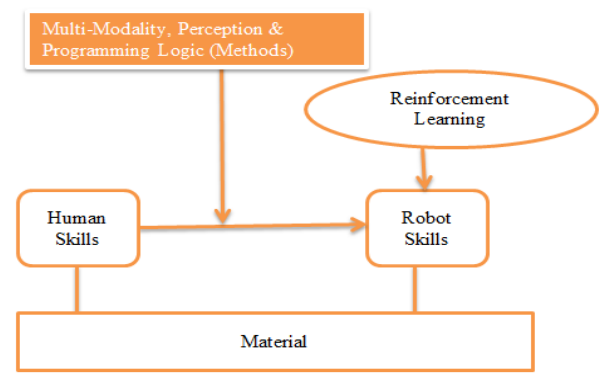

Fig 1:Skill Transformation Between Humans to Robots[5]

The main function of designed methodology is copying the contents of the human mind into robot memory. So, the study of brain structure is primary task \& mandatory for us. As we all know brain is a collection of thousands of neurons with millions of synapses [67] [37]. There is no any static structure of synapses is defined because of static set of synapses is not fixed in human brains. It may change or develop as per age growing or time going that all depend on the experiences [50]. The study of brain structure includes different types of approaches and two most common and popular approaches are direct or indirect [47].It can further uses several methods as an example gradual replacement by parts, reconstruction via scanned method and reconstruction from behavior method [46]. Most of the researchers did the study of Blue Brain Project (BBP) for the complete understanding of brain. It is a type of virtual or artificial brain that shows the overall connections of neurons with synapses in the form of electric map [39] [40]. It is a type of computer based intelligence method that provides a faster access than a biological human [63].

This paper uses Sillicon_Memory [64] _Clock_Chip as an interface for brain computer interfacing [65] during skill transformation from human to robot. The purpose to use brain computer interfacing with brain implant [68] whose function is simple that is read and record all brain activities for further use after the death of the body whose intelligence will be utilized by brain downloading on robot machine [66]. This technology is called "Blue Brain Incredible Technology (BBIT)". While utilizing this technology scientists will easily make new homemade brain control robot Remotes [75]. The most popular method presently used by the A.I professionals is termed as PBDM [12] (Programming by Demonstrator method) [11] that is working for creating mapping applications by considering robots as an interface [9]. These types of methods will further provide a way or path for mind uploading into robot machine [54] [43] [41]. This process is called migration process [45]. As this idea suggested by authors in this paper when this idea will implemented by the robots experts then it will shape into a kind of "Digital Mind". And will work as a MSI (Mind Substrate Independent) [59]. By implemented this new proposed mechanism brain downloading will be quite easier in future. Presently, authors studied several different methods of brain uploading [21] that are discussed below one by one:

$\checkmark$ Gradual Uploading: - This method includes several brain components of nano-transfer. They simply insert nano-devices into human brain for the replacement of neurons at microscopic level [44][51]. The benefit to use this method is direct learning of cells through the information collected from the neurons. In future, it will help to stimulate the behavior of the neurons. Once the construction is complete, the original neuron can be destroyed and the functional analogue can takes place. And this process is repeated for every neuron.

$\checkmark \quad$ Non-Destructive Uploading: - This method retains the original copy in the form of nano-technology. This type of method uses different types of nanodevices whose function is to control the overall mind technology [57]. At first, for controlling mind it will demand for brain scanning by utilizing brain scanners for downloading of brain contents [61].Such type of theoretical technology is called WBE(Whole Brain Emulation) [55][60] [36].

The other benefit to use these above discussed methods is an easy detection of exact neural features that also help to verify happiness centers which do not be combine with the prior knowledge with direct experimentation and investigation. Hence, the re-programming of brain [33] results re-engg of brain [53]. This new designed methodology facilitate us the creation of permanent human brain back-up [62] in the form of mind file. This concept is sometimes named as Digital Immortality [52] [42]. The additional benefit of the utilization of this concept is it saves human time as well as energy [19].The overall working of new designed methodology is named as MRSCC (Mind Reading Silicon Clock Chip) is based on "Store-and-Forward Technique". This new designed technique is divided into two operations viz. Store Operation, Forward Operation that can be discussed below:

Store_Operation: $=$ Once MRSCC (Mind Reading Silicon Clock Chip is inserted into human brain then its working start. Its main function is to copying \& records all the contents that are stored in the memory. The status of store operation can be represented as:

$$
\begin{gathered}
\text { HUMAN_STATUS = ACTIVE_MODE. } \\
\text { ROBOT_STATUS = DE-ACTIVE MODE. } \\
\text { MIND_READING_SILICON_MEMORY_ } \\
\text { CLOCK_CHIP_STATUS }=\text { TRUE. }
\end{gathered}
$$

Forward_Operation: - After collecting the information from human brain silicon memory clock chip will be removed from the human brain and after that inserted into robot memory for copying the contents of human brain that results into permanent human memory back-up in robot machine. The status of forward operation can be represented as:

$$
\begin{gathered}
\text { HUMAN_STATUS = DE-ACTIVE_MODE. } \\
\text { ROBOT_STATUS = ACTIVE MODE. } \\
\text { MIND_READING_SILICON_MEMORY } \\
\text { CLOCK_CHIP_STATUS = TRUE. }
\end{gathered}
$$

This store-and-forward technique may call copy and paste. This method provides a direct method of information transfer from the human brain to robot memory. This process is called mind transfer/mind uploading/mind downloading. Once the movement of human brain to robot machine is possible that it will further considered as a SIM (Substrate Independent 
Mind) [38] [34]. This technology may also call Life Extension or Preservation Technology [48]. This can only be possible with the help of robots. The main purpose of utilization of robots is they are open source programs that actually helps to provide different methods of learning like neural network, motion capture and markov model [82] but the working is only depends on the type of algorithm implemented into it [16] and types of simulator used [82] to run separate types of tasks. Robot can learn different types of skills from humans like object reconfiguration, classification and turn-taking environment [80]. The main purpose is to understand the robot when behave just like humans but independently [83].

The following points must be noted when robots shows their independent behavior while using this new proposed store and forward technique. All are discussed below one by one:

$\checkmark \quad$ Provide Collaborative Learning as an example robot learns from human experience.

$\checkmark \quad$ The robot training will be reduced up to some extent because of robot will learn automatically from human experience by simply followed designed approach that is termed as MRSMCC into it. In this way, you can say this also helps to save human energy.

$\checkmark \quad$ Only Single time time consuming process on the time of logic implementation.

$\checkmark \quad$ A type of portable device like pen drive so sometimes called Plug-and-Play Technique when inserted into robot.

$\checkmark \quad$ Easy to carry because of small in size.

$\checkmark$ Permanent Human Brain back up [62] is easily available. In future if any human memory will getting lost in any accident then some useful information as an example planning about future tasks or business planning's will be easily fetched from it

$\checkmark \quad$ Provides a way for indirect communication by simply following a method of forwarding and transferring skills in unskilled person or disable person [7]. If somebody want to share his or her past knowledge, memories as well as experience. The method follows by them will be termed as Forward-and-Forward" [7] that can be represented in fig.5:

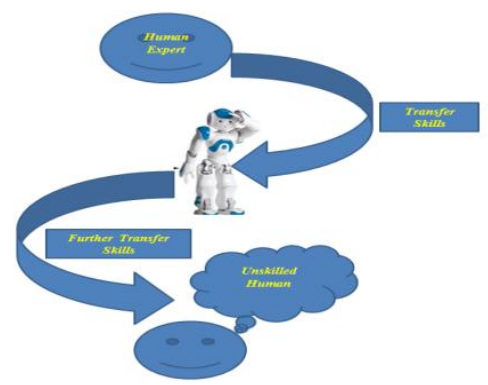

Fig 2: Transference of skills from human expert to robotics and further robotics into un-skilled persons (Forward-Forward Technique)

For the representation of Forward-Forward technique there at several brain chips are available in the market that can be used by simple insertion in the brain that can be shown in fig.3, $4,5,6,7:$

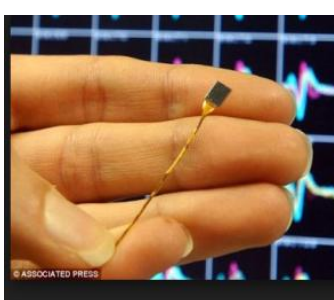

Fig.3: Brain Implant Chip[69]

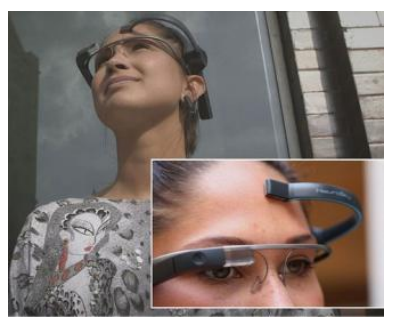

Fig.4:Brain Wave[70][74]

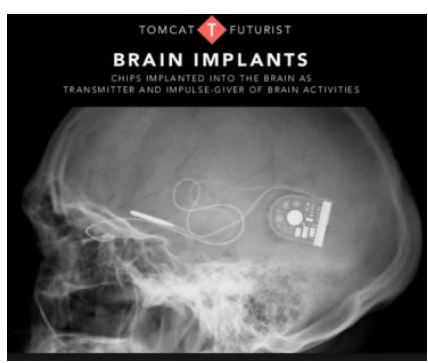

Fig.5: Brain Implant[71]

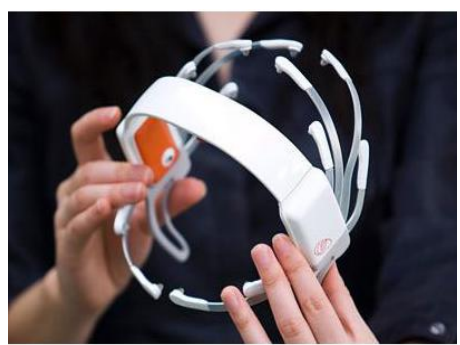

Fig.6: EEG Headset: For measuring Brain Activities [74[76][77]

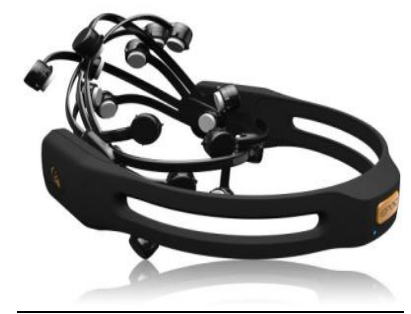

Fig.7:Mind Control Headset: Working Based on Epoc Technology[78]

And the other most practical use of Brain implant Chips can be shown in google glasses that can be represented in fig. 8 and 9: 


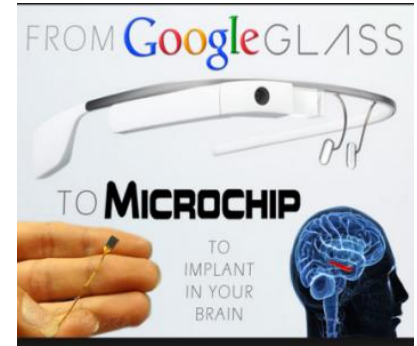

Fig.8: Used In Google Glasses[72]

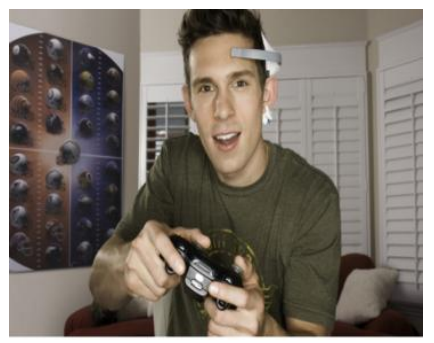

Fig .9: Mind Control Games[79]

\section{REVIEW OF LITERATURE}

(R.K Seth and Rimmy Chuchra et al Jan-2015): This paper discussed about the synergetic interaction among human and robotics by proposing a communication flow methodology by utilizing three different types of interaction modes viz. coexisting, conditional and essential mode. The working of this designed methodology is only depend on the type of input format is applied. The input may either be in the form of analog or digital. This designed methodology facilitates us for providing safer and reliable communication. [1]

\section{RESEARCH DESIGN}

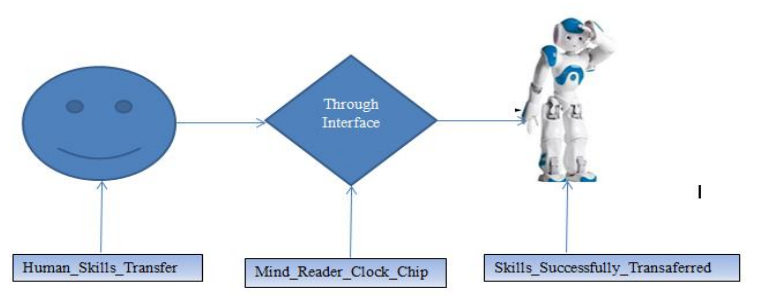

Fig 10: MRSCC Methodology- Skill Transformation from Human to Robot

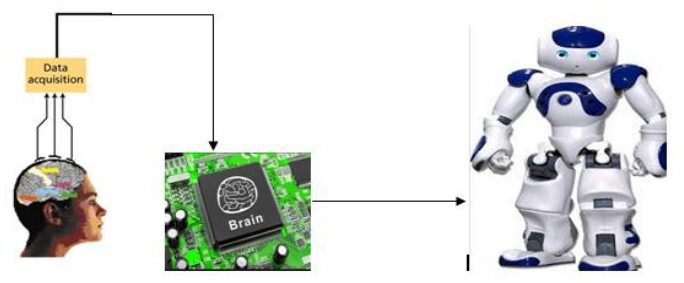

Fig. 11: A Channel for MRSCC

The function of interface is to provide a medium or channel for skill transformation from human to robot. The mapping of human brain with robot shows the reduced activity of computation form human side \& re-produce those computations in code and human brain will live indefinitely (that is you can say millions of years on earth) [35].
This chip store every type of data stored in the different portions of human brain. Normally, Human brain is divided into two portions viz. left brain and right brain. Each portion has own separate functions that can be shown in fig. 12 \& fig.13:
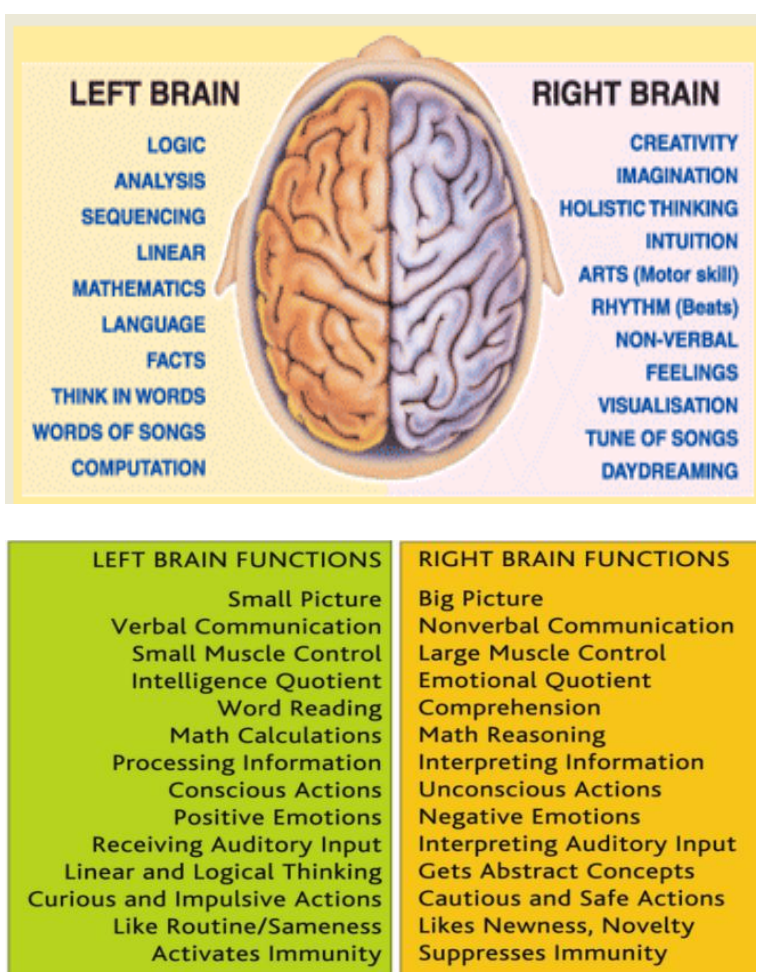

Fig. 12 \& 13: Functions of Left and Right Brain[31] [32]

The function of MRSCC is to create a backup of human memory and stored whole content in own memory. This stored content will be used in future when required. And the most important thing during skill transformation is the use of interface. If the interface is absent then the skill transformation between the human and robot is not possible.

\section{COMMUNICATION FLOW METHODOLOGY}

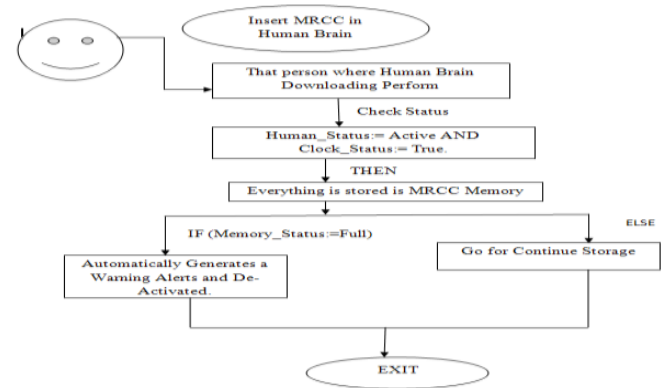

Fig. 14: MRSCC- Shows Communication between human and Robot

\section{CONCLUSIONS}

This paper discussed about the different types of human robot interaction methods and proposed a new method of skill transformation that is named as MRSCC (Mind Reading Silicon Clock Chip). The complete working of this designed methodology depends on store and forward technique. The benefit to use store-and-forward technique is to create a human memory back up (that is brain downloading) by utilizing MRSCC (Mind Reading Silicon Clock Chip). While 
performing store operation human is in ACTIVE_MODE and ROBOT will be on DEACTIVE_MODE and for performing forward operation HUMAN will be on DEACTIVE_MODE and ROBOT will be on ACTIVE_MODE. In both cases the status of CLOCK_CHIP remains same that is TRUE. It indicates enable that is chip is ready to use. This proposed communication flow methodology as developed in this paper provides a closer interaction called Robot Fostering by utilizing interface that is silicon memory clock chip where the function is to store everything whatever is in human brain into its memory until memory full.

\section{FUTURE SCOPE}

In future, this work of skill transformation can be extended by inserting camera in eye contact lens that utilizes smart lens technology. The main function of camera in eye contact lens is to capture all contents or images that are study by human eye either through books or from other relevant sources and correspondingly insert wireless antenna into human head that provide connectivity with the external devices during information exchange. The size of wireless antenna is thicker than the human hair. The main function of wireless camera is to capture all records or contents that are read by human eye. In this way, wireless camera and wireless antenna collectively helps to transfer human skills to robotics in more convenient way rather than first storing and after that forwarding into robot machine.

\section{REFERENCES}

[1] R.K Seth and Rimmy Chuchra, January 2015.Synergetic Interaction among Human and Robotics by Proposing Communication Flow Methodology, International Journal of Computer Applications.

[2] www.cns.atr.jpthren/research.php?topic=5.

[3] Cynthia Brea zeal \& Brain Scassellati, Challenges in building robots that Imitate people, MIT A.I Lab, Cambridge.

[4] Adrian Stoica, 2007. Robot Fostering Techniques for sensory-motor development of humanoid Robots, Robotics and Autonomous Systems, ELSEVIER.

[5] Alberto Montebelli \& Ville Kyrki, Transferring Physical skills from humans to robots: Multi-Modal Programming by Demonstration for In-Contact Tasks, Aalto University, Finland.

[6] Pefernel.L,Deptt of Autom, Jozef Stefan Inst, May 2013. Humanoid Robot Posture Control Learning in real time based on human Sensor motor Learning ability, IEEE International Conference.

[7] Jorge Solis,Simone Marches-CHI, Antonio Frisoli Charlo Alberto Avizzano, Reactive Robot System Using a haptic Interface : An Active Interaction to Transfer Skills from the robots to Unskilled Persons, Italy.

[8] www.mayacakmak.com/research.

[9] Monica N.Nicolescu, Maja Mataric, Task Learning through Imitation \& HRI Models \& mechanisms of imitation and social learning in robots, humans and animals.

[10] Fei Chao, Zhengshuai Wang, Changing Shang, Quinggang Meng, Min Jiang, November 2014.A developmental approach to robotic pointing via humanrobot interaction, ELSEVIER, Information Sciences ,New trend of Computational Intelligence in HRI.
[11] Thomas hulin, Carsten Presche, Eldad Yechian, Ariel Telpaz, Volker Schmiragel \& Uwe E, Zimmermann, 2011. Haptic and Visual Training of system behavior-A case Study for robotic Programming by Demonstration, $\mathrm{BIO}$ web of conferences

[12] A.Ajoudani, N.G.Tsagarakuis and A.Bichhi, TeleImpedence: Towards Transferring Human Impedance Regulation Skills to Robots.

[13] Leonel Rozo, Sylvain Calinon, Darvin G.Caldwell, Learning force and position Constraints in Human-robot Co-operative Transformation, Idiap Research Institute.

[14] Albert Ali Salah, Javier Ruiz-del-solar, Centin Mericli and Pierre-Yues Oudeyer, 2012. Human Behavior understanding for robotics, Flowers Research Team, INRIA Bordeaux Sud-Ouest, France, Springer.

[15] Stefano's Nikolaidis, Julie Shah, Human-robot cross training: Computational Formulation, Modeling and Evaluation of a human Team Training strategy, Massachusetts Institute of Technology, Cambridge.

[16] motherboard.vice.com/blog/humanoid-robots-aregetting-really-good-at-making-art.

[17] Horizon-magazine.eu/article/robot-rescuers-help-savelives-after-disaters-en.html.

[18] Mulligan, I.Jane, Grudic: Gregory Mulligan, I. Jane, University of Colorado at Boulder, Human to robot skill transfer, US.

[19] www.christian-penaloza.com/index.php/projects/cloud

[20] wee Wang, Benjamin Johnston, Mary-Anne Williams,2012. Social Networking for robots to share knowledge, Skills and Know-how, Springer.

[21] Yiannis Demiris, Andrew Melt off, 2008. The robot in the Crib: A Developmental Analysis of Imitation Skills in Infants and Robots Published Carline I Wiley Interscience, USA.

[22] neuralrehabilitation.org/Projects/Biomet/research.html.

[23] Pedro Neto, Nuno Mendes, Ricardo Arajuo, High-Level robot Programming based on CAD: Dealing with unpredictable Environment, Deptt. Of Mechanical Engg, University of Coimbra, Portugal.

[24] Alexander Morte, Tamara Lorenz, Sandra Hirche, April 2014.Phythm Patterns Interaction-Synchronization Behavior for Human-Robot Joint Action.

[25] www.master-ris-unina.it/Index.php?option=Com-Content and View=article \&id=72 \& Itemed=77 \& Langen.

[26] Hao Ding, Control of robotic system for safe interaction with human operators, Proceeding of the twenty second International Joint Conference on A.I,Institute of Control system theory, Germany.

[27] O.Deniz, A.Falcon, J.Mendez, M.Castrillon, Useful Computer Vision Techniques for Human Robot Interaction , Universidad De Las Palmas De Crran Canaria, Spain.

[28] Sonia Chernova, Nick Depalma, Elisaveth Morant, Cynthia Breazeal, Crowdsourcing Human Robot Interaction: Application from Virtual to Physical world. 
[29] Tamie Salter, Kerstin Dautentratun, Rene Teboekhorst, 2006. Learning about Natural Human-Robot-Interaction Styles, Robotics and autonomous Systems, ELSEVIER.

[30] Michael A. Goodrich, Alan Schultz, 2007. Human Robotics-Interaction and Trends I Human Computer Interaction,.

[31] https://www.google.co.in/search?hl=en\&tbm=isch\&q=hu man+brain+left+portion+and+right+portion+\&ei $=5 \mathrm{~m} 9 \mathrm{Q}$ VYJVhfxSvJ6BqA8\#imgrc=3KA6PujwT11AMM\%253 A\%3B9tFRLQ73aEzARM\%3Bhttp\%253A\%252F\%252 Fqph.is.quoracdn.net\%252Fmain-qimg f62e9005a094b672361d628a23ca8e22\%253Fconvert_to _webp\%253Dtrue\%3Bhttp\%253A\%252F\%252Fwww.qu ora.com $\% 252 \mathrm{FHow}$-can-you-stop-being-controlled-byyour-emotions\%3B354\%3B 199.

[32] https://www.google.co.in/search?hl=en\&tbm=isch\&q=hu man+brain+left+portion+and+right+portion $+\&$ ei $=5 \mathrm{~m} 9 \mathrm{Q}$ VYJVhfxSvJ6BqA8\#imgrc=9igcOk2YBzfsM\%253A\%3 BrCqAVi8A3xrdZM\%3Bhttp\%253A\%252F\%252Fwww .online-sciences.com\%252Fwp content $\% 252$ Fuploads $\% 252 \mathrm{~F} 2015 \% 252 \mathrm{~F} 01 \% 252 \mathrm{Fbrain}$ 4.jpg\%3Bhttp $\% 253 \mathrm{~A} \% 252 \mathrm{~F} \% 252 \mathrm{Fwww}$.onlinesciences.com\%252Fthe-living-organisms $\% 252$ Fthestructure-and-function-of-the-brain-in-the-centralnervous-

system $\% 252$ Fattachment $\% 252$ Fbrain $4 \% 252 \mathrm{~F} \% 3 \mathrm{~B} 1646$ $\% 3 \mathrm{~B} 1114$.

[33] https://lifeboat.Com/ex/benifits.of.mind.uploading.

[34] www.minduploading.org.

[35] www.dailymail.co.uk/sciencetech/article-2879803/TheScientists-Planning-Upload-Brain-COMPUTERResearch-allow-inhabit-Virtual-Worlds-liveforever.html.

[36] philosophicaldisquisitions.blogspot.in/2014/09/chalmorsvs-pigliucci-on-philosophy-of.html.

[37] www.softmachines.org/wordpress/?p=1558.

[38] Prof.Robert M.Geraci, 2013. Mind Uploading, Springer.

[39] dada.cca.edu/ acompeau/mind-uploadingcontents/Mind-uploading-Content.pdf.

[40] dada.cca.edu/ acompeau/mind-uploadingcontents/Mind-uploading-content.pdf.

[41] https://www.fightaging.org/archives/2014/01/a-littlephilosopy-of-mind-uploading.php.

[42] Yoonuck Choe, Jaerock Kwon and Ji Ryang Chung, June 2012.Time .Consciousness and mind uploading, Mind uploading special issue, International journal of Machine Consciousness world scientific publishing company.

[43] Kaj Sotala, Advantages of Artificial Intelligence-Upload Digital Minds, University of Helsinki, MIRI (Machine Intelligence Research Institute).

[44] Scott Douglass, Christian Liberec and Yulin Quin, 2004.An Integrated Theory of Mind, American Psychological Association..

[45] V.Astakhov, Continuation of Consciousness: Mind Uploading and Resurrection of Human Consciousness, Is there a place for Physics, Neuroscience and Computers?
[46] Philosophicaldisitions.blogspot.in/2014/01/how-manymethods-of-mind-uploading.html.

[47] Alexander Borzenko, Indirect Mind Upload, Proto-Mind Machines Inc.

[48] www.carboncopies.org/the-history-of-sim-whole-brainemulation-and-mind-uploading.

[49] Netabrary.net/articles/mind-uploading.

[50] www.mind.ilstu.edu/curriculum/extraordinaryfuture/phillinpsch4.php.

[51] www.slideshare.net/anupamnirvikar/mind-uploading15232036 .

[52] www.thewtftimes.com/back-up-your-mind-digitalimmortality/

[53] www.authorstream.com/Presentation/Saitya.Kaveti1401539-Coginitive-Computing-Mind-Uploading/.

[54] help.sap.com/saphelp-er60 sp/helpdata/en/5c/2a2d585658a45bb7ebcaef49589e4/con tent.htm.

[55] Daneil EM, Jaun-carlos foust, Brandon Whale,2013. The Prospectus of Whole Brain Emulation (WBE) within next half century, Journal of Artificial General Intelligence.

[56] https://blog.bufferapp.com/how-to-rewire-you-brainsfor-positivity-and-hapiness.

[57] beforeitsnews.com/conspiracytheories/2012/01/mind.con trol-methods-of-illuminati-1676330.html.

[58] Ben goertzel, 2012. When two minds should be considered versions of one another, 1405 Bernard Place, Rockville MD20851.

[59] Sim Bamford, A Framework for approaches to transfer of a mind substrate.

[60] Anders Sandberg, 2013. Feasibility of whole brain simulation, Theory \& philosophy of artificial intelligence, Springer.

[61] Aaron Nowaczek, 2014. Kurzweil's unfermented Wine:Copying brain and other speculations, Nipissing University, Ephemeris.

[62] www.politicalforcum.com/science/398813-mindupload.html.

[63] www.technologyillustratedmagazine.com/q/mindtransfer.

[64] www.futurelec.com/sillicon_chip_2015.

[65] www.silliconchip.com.au/issue/2015/january.

[66] en.wikipedia.org/wiki/Brain Implant.

[67] www.mind.ilstu.edu/curriculum/extraordinary_future/phi llipsch2.php?modGUI=247\&CompGUI=1944\&itemGUI $=3397$.

[68] https://www.youtube.com/watch?v=vgpXErYypqE.

[69] https://www.google.co.in/search?hl=en\&site=imghp\&tb $\mathrm{m}=\mathrm{isch} \&$ source $=\mathrm{hp} \& \mathrm{biw}=1366 \& \mathrm{bih}=623 \& \mathrm{q}=\mathrm{image}+$ for + foot + print\&oq $=$ image + for + foot + print\&gs_l $=$ img. $3 \ldots 82$ 24.13558.0.13873.20.18.0.0.0.0.466.2531.3 6j1.7.0.ekpsrh...0...1.1.64.img..15.5.1854.t1AKoHfAfcI\# $\mathrm{hl}=$ en\&tbm=isch\&q=brain+implant+chip+images\&imgr 
$\mathrm{c}=2 \mathrm{cf} 75 \mathrm{eStnTpatM} \% 253 \mathrm{~A} \% 3 \mathrm{~B} 0 \mathrm{AfEsJIdHRTbM} \% 3 \mathrm{Bhtt}$ p $\% 253 \mathrm{~A} \% 252 \mathrm{~F} \% 252 \mathrm{Fdcclothesline.com} \% 252 \mathrm{Fwpconte}$ nt $\% 252$ Fuploads $\% 252$ F2013\%252F07\%252Fa-chip-inyour-

brain.jpg\%3Bhttp $\% 253 \mathrm{~A} \% 252 \mathrm{~F} \% 252 \mathrm{Fwww}$.dcclothesli ne.com\%252F2013\%252F07\%252F22\%252Fgooglewants-to-implant-chips-into-ourbrains $\% 252 \mathrm{~F} \% 3 \mathrm{~B} 500 \% 3 \mathrm{~B} 301$.

[70] https://www.google.co.in/search?hl=en\&site=imghp\&tb $\mathrm{m}=$ isch\&source $=\mathrm{hp} \& \mathrm{biw}=1366 \& \mathrm{bih}=623 \& \mathrm{q}=$ Thanks\&o $\mathrm{q}=$ Thanks\&gs_l=img.3..018j0i10j0.700.2285.0.2363.8.7. 0.0.0.0.340.340.31.1.0.ekpsrh...0...1.1.64.img..7.1.339.F $\mathrm{MjRlBh} 8 \mathrm{t} 7 \mathrm{w} \# \mathrm{hl}=\mathrm{en} \& \mathrm{tbm}=\mathrm{isch} \& \mathrm{q}=\mathrm{images}+$ for $+\mathrm{mind}+\mathrm{h}$ ead+set+control+technology\&imgrc $=$ oolmxiBHuEVdT M\%253A\%3BMLJof5ViqRnSM\%3Bhttp\%253A\%252F \%252Fi2.mirror.co.uk\%252Fincoming\%252Farticle 3835 674.ece\%252FALTERNATES\%252Fs615\%252FGoogle -Glass

Main.jpg\%3Bhttp\%253A\%252F\%252Fwww.mirror.co.u k\%252Fnews\%252Ftechnologyscience\%252Ftechnology $\% 252 \mathrm{Fgoogle}$-glass-sensor-uses-power $3836379 \% 3 \mathrm{~B} 615 \% 3 \mathrm{~B} 409$.

[71] https://www.google.co.in/search?hl=en\&site=imghp\&tb $\mathrm{m}=\mathrm{isch} \&$ source $=\mathrm{hp} \& \mathrm{biw}=1366 \& \mathrm{bih}=623 \& \mathrm{q}=\mathrm{image}+$ for + foot+print\&oq=image+for+foot+print\&gs_l=img.3 ...82 24.13558.0.13873.20.18.0.0.0.0.466.2531.36j1.7.0.ekpsr h...0...1.1.64.img..15.5.1854.t1AKoHfAfcI\#hl=en\&tbm= isch \&q=brain+implant+chip+images\&imgrc $=1$ UWOP6v RCie7jM\%253A\%3BwFKiXtSNPvmJeM\%3Bhttp\%253 A\%252F\%252Fimage.slidesharecdn.com\%252Fbrainenh ancement-140910091444

phpapp01\%252F95\%252Fbrain-enhancement-the-roadto-superintelligence-16 638.jpg\%253Fcb\%253D1410342065\%3Bhttp\%253A\%2 52F\% 252Fwww.slideshare.net\%252FThomasKlaffke\%2 52Fbrainenhancement\%3B638\%3B 451 .

[72] https://www.google.co.in/search?hl=en\&site=imghp\&tb $\mathrm{m}=\mathrm{isch} \&$ source $=\mathrm{hp} \& \mathrm{biw}=1366 \& \mathrm{bih}=623 \& \mathrm{q}=\mathrm{image}+$ for + foot+print\&oq=image + for + foot + print\&gs_l=img.3...82 24.13558.0.13873.20.18.0.0.0.0.466.2531.36j1.7.0.ekpsr h...0...1.1.64.img..15.5.1854.t1AKoHfAfcI\#hl=en\&tbm= isch\&q=brain+implant+chip+images $\&$ imgrc $=016-$
bVM4g4_MhM\%253A\%3B8LBaypbQnEqh4M\%3Bhttp $\% 253 \mathrm{~A} \% 252 \mathrm{~F} \% 252 \mathrm{~F} 1 . b p . b l o g s p o t . c o m \% 252 \mathrm{~F}-\mathrm{nA} 7$ ZFw7JdE\%252FUfYU_UhjJOI\%252FAAAAAAAABT M\%252FoBNe0TkWjc\%252Fs1600\%252FProphecy_\% 252BGrom $\% 252$ BGoogle $\% 252 \mathrm{BGlass} \% 252 \mathrm{Bto} \% 252 \mathrm{~B}$ Microchip\%252BImplant\%252Bin\%252Byour\%252BBr ain.jpg\%3Bhttp\%253A\%252F\%252Fcambraza.blogspot. com\%252F2013\%252F07\%252Fprophecy-from-googleglass-to-microchip_30.html\%3B1000\%3B701.

[73] http://futuristmm.com/future-technology/brain-hackingtechnologies-are-the-future/.

[74] http://www.seriouswonder.com/eeg-headsets-rule-thefuture-with-your-mind/.

[75] http://www.tinkernut.com/portfolio/homemade-mindcontrolled-tv-remote/.

[76] http://www.syncni.com/news/2/4632/why-eeg-headsetsare-taking-the-technology-world-by-storm/tab/1356.

[77] http://news.yahoo.com/blogs/technology-blog/mindcontrolled-skateboard-literally-powered-thoughts221449460.html.

[78] http://www.trustedreviews.com/opinions/controlissues_Page-7.

[79] http://www.gameinformer.com/b/news/archive/2012/03/ 06/neurosky-mind-controlled-games.aspx.

[80] Darwin G.Caldwell, Petar Kormushev and Seyed Reza Ahmadzadeh, Interative robot Learnning of Visuospatial Skill, Istituto Italiano di Tecnologia, Genova.

[81] Peter Wolf, Robert Richer, Mark Van raai,Francesco crivelli, Claudio Koch, Roland spirits and Georg Rauter, Transfer of complex skill learning from virtual to real rowing.

[82] www.takanishi.mech.waseda.ac.jp/top/solis/transferskills , GTSS.html.

[83] Williams.M, Johnston.BG, Wang.W, 2012. Social Networking for Robots to share knowledge, Skills and know-how. http://hdl.handle.net/10453131527. 